\section{The GDC - lifting the lid. Part 4: fitness to practise}

\author{
H. Mathewson ${ }^{1}$ and D. Rudkin ${ }^{2}$
}

VERIFIABLE CPD PAPER
IN BRIEF

- Details of the General Dental Council's role in investigating complaints about dental practitioners.

- Outlines the fitness to practise process from initial complaint to final decision.

- Looks at the roles of some of the many people involved with the fitness to practise system.

As an organisation whose function is to protect the public, the General Dental Council's role in investigating complaints about dentists and dental care professionals dealing suitably with those who have been shown to practise in an unprofessional or dangerous manner is obviously of paramount importance. This article looks at the GDC's fitness to practise procedures - the system that looks into complaints and allegations of malpractice about dental practitioners. It outlines the different stages in the process and introduces some of the many people involved with the efficient running of this vital service.

Mike Ridler's late father was a dentist, with a single-handed NHS practice in Cornwall. He was one of the few dentists to be awarded the Military Cross, serving with the Paras in North Africa and Sicily and at Arnhem.

So when Mike (Fig. 1) says 'we're not running an anti-dentist crusade' he will be telling the truth. Which is just as well, because as the head of our hearings team, Mike is in charge of ensuring that the GDC's fitness to practise procedures work in practice.

What Mike does not know about fitness to practise is not worth knowing. When he arrived at the GDC at the beginning of 1999, it was after nearly 25 years as a civil servant at the Ministry of Defence

THE GDC - LIFTING THE LID
1. Professionalism and standards
2. Registration
3. Education, CPD and revalidation
4. Fitness to practise
5. Illegal practice

President, ${ }^{2 *}$ Chief Executive and Registrar, General Dental Council, 37 Wimpole Street, London, W1G 8D0 ${ }^{*}$ Correspondence to: Mr Duncan Rudkin Email:drudkin@gdc-uk.org

Refereed Paper

DOI: 10.1038/sj.bdj.2008.623

${ }^{\circledR}$ British Dental Journal 2008; 205: 95-99 and Department of Transport. 'My dentist father was in his 80s and long since retired when I arrived at the GDC, but was still very interested in my move, not to say amused,' recalls Mike. Ask Mike what the fitness to practise (FtP) regime is for, and he does not hesitate: 'The task of the FtP procedures is to fulfil the function of the GDC, which is to protect the public.'

Sift through back copies of the GDC Gazette and the tales are all there. They make grim reading. The dentist without professional indemnity who failed to relieve persistent, severe dental pain. The dentist who fraudulently claimed 20 times for treatment and disposed of a lesion from a patient's face without arranging for analysis to check whether it was a matter for concern. One dentist deliberately damaged orthodontic appliances in order to defraud. Another showed no concern when a patient fainted. Forgery... bullying and sexual harassment... failure to obtain informed consent... unnecessary treatment and exposure to radiation... incompetence. When so many dentists are competent, conscientious professionals in whom their patients can and do have utter confidence, this litany of delinquency is saddening.

Justice has been done in each of these cases, but we still take no pleasure in recalling any of them. Neither, we know, will you. Your standing suffers each time a case is publicised. But the public must be protected, and none of these cases is negligible. So how does the fitness to practise regime work?

\section{Considering allegations}

The GDC, as you know, can consider complaints from patients or information from other organisations, such as the police or the NHS, that raise concerns about a registered dental professional. The task of considering whether an allegation raises an issue for the GDC falls to Julian Carpenter and his case workers. Julian (Fig. 2), who used to work for the NSPCC, is Head of Fitness to Practise at the GDC. He's been with the GDC for 12 years.

If you provide information on a dentist's fitness to practise, or if you are the subject of an allegation, then a member of Julian's team will be your main point of contact. It is up to the caseworkers to enquire into complaints and allegations, instruct the GDC's lawyers where necessary, and follow up on decisions.

'At the preliminary stage, we ask only "does this information appear to raise a question that needs to be looked into?"” says Julian. 'There's nothing more to it than that.' No decision is made at this stage about whether an allegation is true.

Caseworkers are under an obligation to deal with allegations and concerns made against registrants thoroughly and without unnecessary delay and to 
ensure that the investigation process is made clear to everyone, treating all parties with respect and courtesy. They assess all evidence objectively and the investigating process is fair and transparent. Only sensitive health information is concealed.

Investigating is, however, part of their brief. 'It's a million miles from when I first arrived,' recalls Julian. 'Originally, we were administrators, then case workers, and now we're developing the role to include some investigation work, such as taking witness statements and so on. The environment and the challenges it presents changes all the time.

'My caseworkers often need to be quite persistent, like detectives. Some cases can be hard to nail down, and we don't have police powers, obviously. You need a certain doggedness and resilience. Clearly, we see the seamy side of dentistry where some dentists are at fault, so our training aims to help us keep a sense of balance. We never jump to conclusions about people and we know that being fair means hearing all sides of any story.'

Some dentists are truly shocked by allegations against them, even if they have had trouble with a patient or patients. 'Complaints can be unfounded and even malicious. We have to be evenhanded.' Sometimes dentists can be evasive. Most co-operate fully. Others do not. 'The fact is that the process is set down by law, so no-one can escape. If we didn't do it, we'd be failing in our own duty: and don't forget that we're overseen ourselves by the Council for Healthcare Regulatory Excellence.'

Ten per cent of the information coming to Julian and his team comes from other registrants, up fourfold in five years. 'Whistleblowing reflects not just the GDC's clear guidance on protecting patients and enhanced protection for whistleblowers, but a growing intolerance of bad apples within the profession.

'If you have concerns about a fellow practitioner, contact us as early as possible. You can talk to us anonymously initially, but it's natural justice that a registrant should know who their accuser is. If you have evidence, you have a professional duty, and a duty to the public, to disclose it.

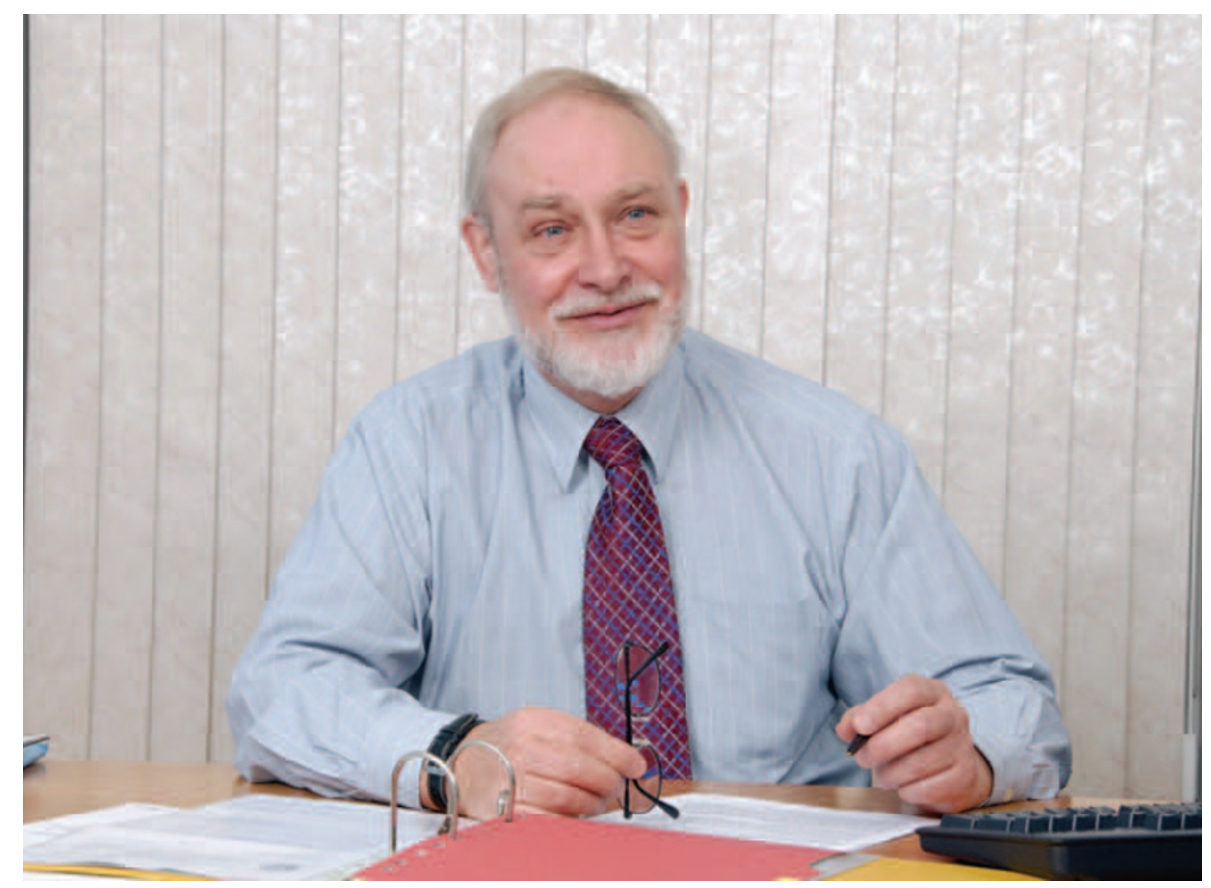

Fig. 1 Mike Ridler heads the hearings team

Often 'a number of people and agencies might have different pieces of the jigsaw, but don't share them, and abuse can continue unchecked.' Julian theorises that in 'nests of bad practice', poor dental practice is tolerated or even encouraged. When someone starts up or moves to a new practice, they tolerate or encourage the bad practice they have come to accept as normal.

To build as complete a picture as possible, Julian's team works closely with the police, primary care trusts and others. We also share information with our European partners. But it is not straightforward. The principle of protecting the public can conflict with the principles of data protection and freedom of movement.

\section{Committees and the Fitness to Practise Panel}

We have no truck with 'fishing expeditions' - which is what our learned friends call it when people start trawling for trouble to 'get at' a professional in an unfair way. If a case seems to be merited, staff forward it to the Investigating Committee to consider further whether a registrant's fitness to practise may be impaired due to health, conduct (including convictions and cautions) or performance. The Investigating Committee is responsible for deciding which of the three committees to refer a case to - conduct, health or performance (see Fig. 3).

If there $i s$ to be an inquiry, should the dentist be suspended until then, or work under conditions? The Investigating Committee may ask the Interim Orders Committee to decide. If there is no referral to a practice committee, the Investigating Committee can give advice or a warning.

Mike Ridler's hearings team are physically and administratively separate from the investigation side. They make sure the Professional Conduct Committee (PCC) and other practice committees run smoothly, efficiently and fairly.

'Within the parameters of natural justice, we effectively run trials,' says Mike of a full public hearing before a practice committee. Originally, the Council set standards and PCC members came from among its own ranks, leading to fears that it was acting as judge and jury. Since 2003, the GDC has continued to set standards and raise concerns about apparent breaches of them. But members of the external, independent Fitness to Practise Panel have made the final decisions.

If allegations are proved, the committee decides whether a registrant is unfit to practise and what action to take, including striking a registrant off the register. 'We're not on a crusade. We're neutral, just trying to be fair. We want the right outcome: a fair outcome, which might or might not be a "conviction".' 


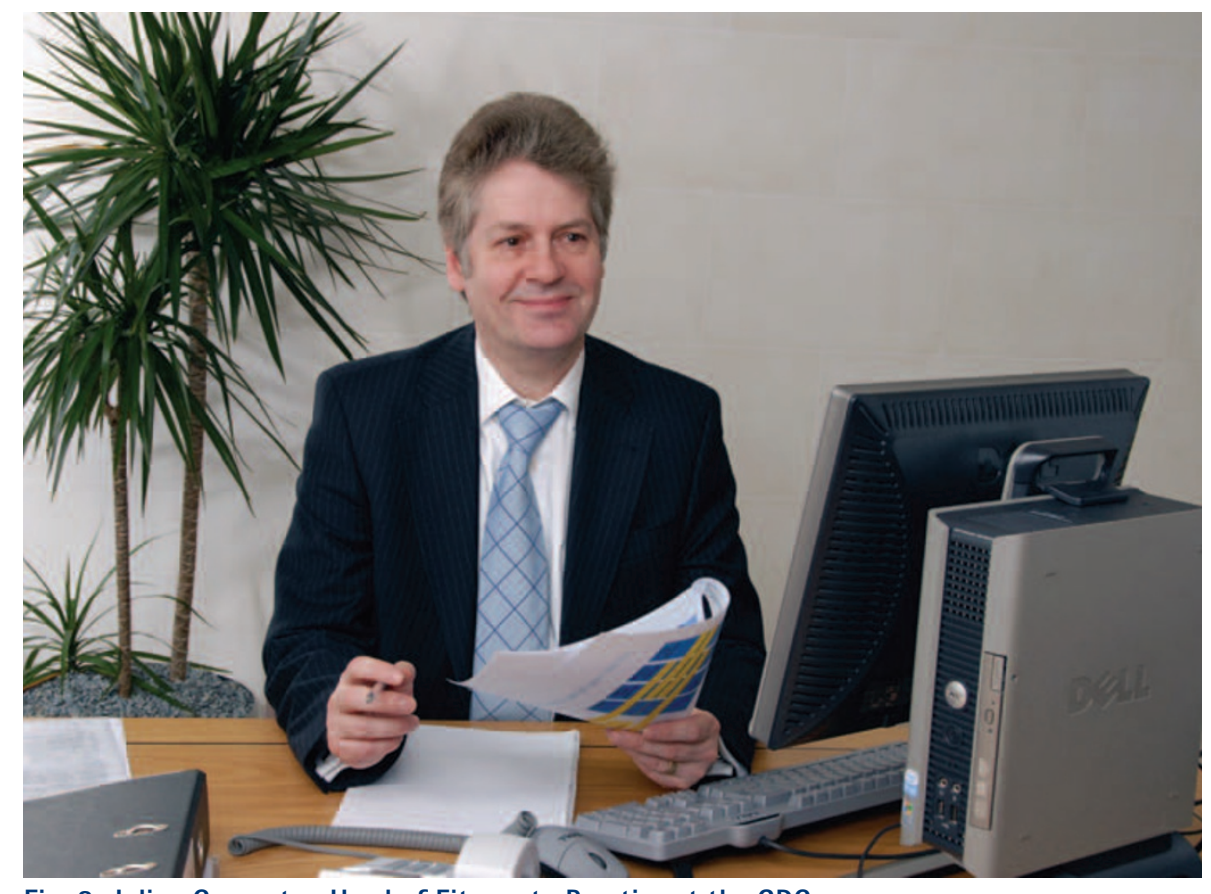

Fig. 2 Julian Carpenter, Head of Fitness to Practise at the GDC

'We', of course, is not just Mike, but the entire independent panel. 'Although their work is funded by Council, members of the panel can't be disciplined or dismissed by Council, only by the independent Appointments Committee. So they are genuinely independent. That's an important safeguard.' The 76 dentist, dental care professional (DCP) and lay members of the panel are all recruited in the same way, to the same standards, against the same criteria, and given the same training and appraisals.

He is a great fan of the panellists. 'They're terrific. They really do a superb job.' Professors of dentistry, general dental practitioners, DCPs and specialists, practising or perhaps recently retired, make up the professionals. Lay members often have portfolio careers and may be magistrates or have a background in healthcare or accountancy. All, professional and lay, have a sense of public duty, including their duty to protect the public, within the bounds of fairness and justice.

When a committee sits, Mike or one of his team acts as committee secretary to the five members (a quorum is three, of whom one must be a dentist). Any known conflicts of interest will have been weeded out. They work as a team.

Says Mike: 'Knowing what I know, if I were a dentist sitting in the respondent's seat, I would be confident that I would receive a fair decision. They are a great bunch of people doing what can be a very unpleasant job well. No one likes bringing careers to an end. But their job is to protect the public. That said, the "right" outcome may be to find the facts proved, but declare that the dentist is not "impaired" (as the law puts it), given the circumstances. A panel can be as satisfied with that as with erasing a dentist who's gone to the bad.'

The task of a practice committee is certainly not to prove every case against a dentist. 'We're not collecting scalps,' says Mike. A practice committee may measure health, conduct or performance against GDC standards, but is not bound by them, just as its members listen to prosecution and defence lawyers but then act as they think fit. Appeals set precedents, but there is no tariff that says, for instance, failure to obtain consent from a patient must lead to erasure.

There is no denying that appearing before a practice committee can be an ordeal. There are lawyers involved - never an enticing prospect - but 'the prosecution and defence are encouraged to explain the issues in words everyone can understand,' says Mike. 'Nothing is so complex that it can't be explained in terms of right and wrong. Cases rarely rest on a technicality.'

Every decision is open to challenge by way of appeal to the High Court: by the

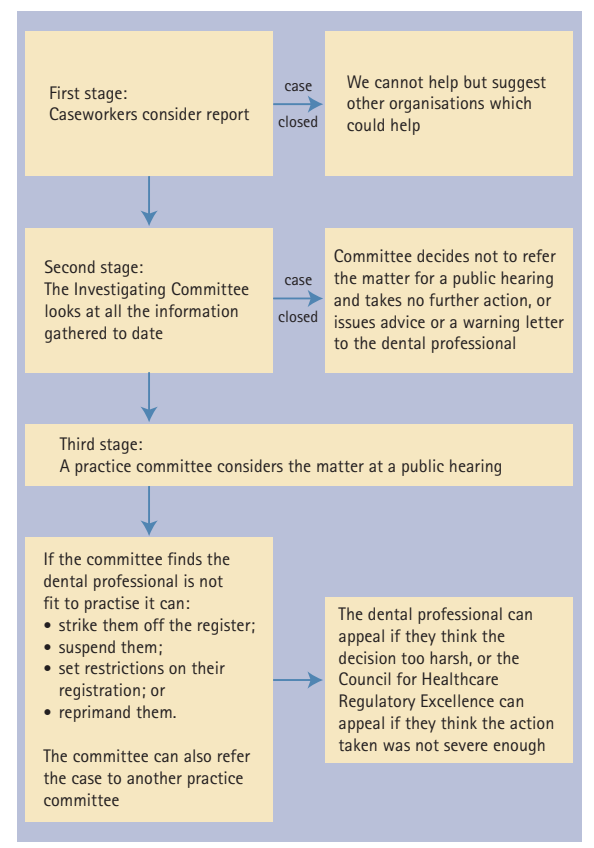

Fig. 3 Flowchart of the stages in a fitness to practise investigation

dental professional, if he or she feels that a decision is too harsh, or by the Council for Healthcare Regulatory Excellence, if it feels a decision has been too lenient. 'In seven years, I can recall three or four successful challenges, out of literally hundreds of cases.'

Hundreds of cases, yes, but to put that in perspective, of the 35,000 dentists on the register, some 30,000 are active. Next year, Mike expects to deal with 100 cases. That means that the chances of being a respondent are just 1 in 300 .

\section{'Ten easy ways to appear before a hearing'}

Clearly, it is right and just that many complaints do not reach a hearing. Other complaints are wholly justified. For starters, Mike lists ten 'easy ways' to appear before a hearing. 'The quickest is to get a serious criminal conviction.

'Dangerous sedation practice, poor infection control, consent issues - these crop up in many cases. Clearly, sexual assault and accessing child pornography are always treated seriously. Most cases involve more than one issue.'

Very few come to a hearing by accident - there tends to be a reason for them. Often they could have been nipped in the bud early on. 'At least half the cases result from failures of communication - with patients, failure to explain what the dentist is doing and why; with staff; 
and, in a wider sense, with the profession, when the dentist just loses touch.'

As a dentist, Mike Ridler's father was 'a fine and upstanding pillar of the community, but then, all his colleagues were too.' You might think that the rise in conduct cases suggests otherwise. Does it? Less than a decade ago, there were a dozen cases a year, considered over eight days in May and eight in November. Now practice committees sit virtually nonstop: 360 hearing days are planned for this year. There were 60 cases in 2006 and 80 last year. This year, we expect 100. Why the rise? We think it's down to a range of factors.

First there are more dentists, many from overseas, who may be employed by practices which do not support or train them, some of which are operating on the margins of acceptable practice, to put it politely. And like the rest of us, many dentists have financial pressures bearing down on them. For some it becomes too much.

The other side of the coin is that the public are complaining more, partly because they are being encouraged to. They also find it easier. Here is an example: we scrapped the need to swear a statutory declaration before a solicitor. This was an arbitrary and discriminatory barrier which deterred some patients, including many with genuine complaints. Media reporting plays its part in encouraging more complaints, as do lawyers. But is that bad? Throughout most of the 20th century, people did not complain because they did not see the point - the professions would 'protect their own'. 'Trust me, I'm a doctor' no longer cuts the mustard. There has been a sea change.

Alas, there is no doubt that a small number of registrants are rogues. You get them in every walk of life. They let their patients and colleagues down, and it is them we target. Others hopefully get back on track, through the Dentists' Health Support Programme (formerly the Sick Dentist Scheme - phone confidentially on 01327262 823). Support of this kind makes sense. Suspending or erasing a dentist with health problems loses all the money spent on training them and wipes out their future contribution. Most can be helped or rehabilitated.

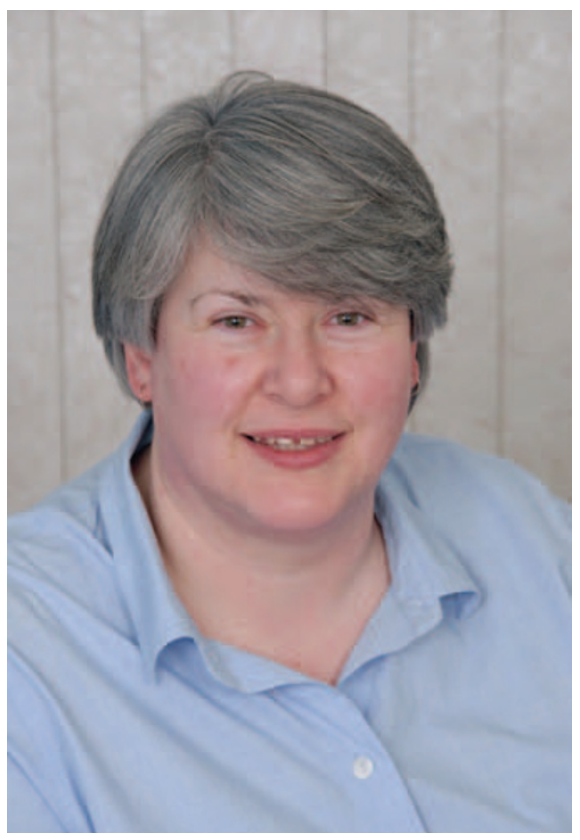

Fig. 4 Fitness to practise case worker Margaret Peecock

\section{The Dental Complaints Service}

What if a patient's complaint does not give rise to any concern about a dental professional's fitness to practise? Perhaps a new denture just is not comfortable, or the practice has cancelled an appointment at short notice and not taken the time to explain why or give the patient an alternative date. In instances where a patient wants a simple apology, an explanation, or for the practice to put right something that has gone wrong, resolution is usually and most quickly achieved through a practice's own complaints handling procedures.

For NHS dental patients, the NHS has long had a complaints scheme which supports local resolution in the first instance, and takes forward complaints which cannot be resolved at practice level. Since May 2006, the Dental Complaints Service, set up and funded by the GDC although operationally independent of it, has assisted over 2,500 private patients and their dental professionals to resolve complaints about private dental care.

\section{Some more members of the FtP team}

'A lot of people believe we have a hit squad that we send in - they make a complaint today and the dentist's practice is closed down tomorrow.' It is up to Margaret Peecock (Fig. 4), a fitness to

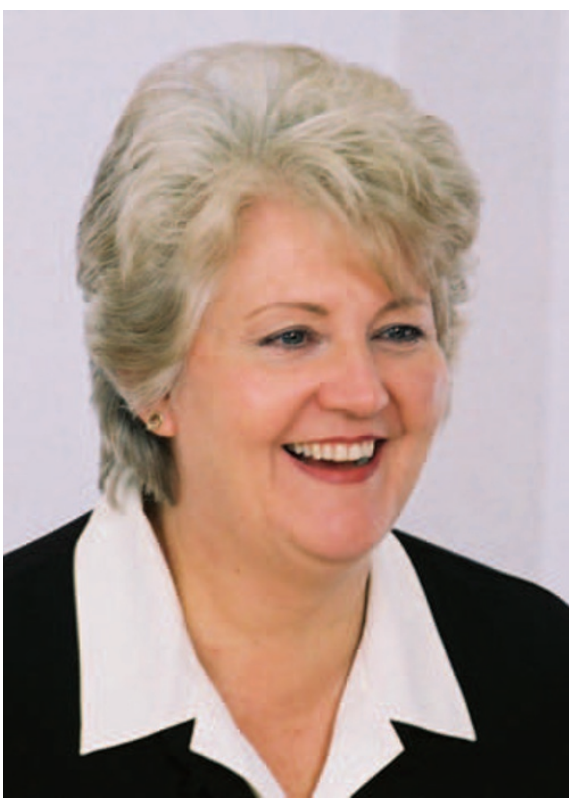

Fig. 5 Rosemarie Khan, a DCP member of the GDC who serves on the Investigating Committee

practise case worker, to manage expectations like this. It cannot be easy.

When callers are agitated or emotional, 'we let them say what they have to say. They can sometimes feel traumatised by what's happened in the dental chair, and they're calling for resolution or advice. We try to find a way forward.

'No two cases are the same. What could be thought rude by one patient may be shrugged off by another. We encourage people to come forward and have a chat rather than to worry. It's a busy office but there's always someone available to speak to a patient or dental professional with a concern. It's good that both sides feel they can contact us. That's what we're here for.

'We take every call seriously, because if someone's taken the trouble to call, it's serious to them and we respect that.' But there may be other avenues of support, or a GDC case may be inappropriate. Sometimes, just talking resolves the issue.

If a referral seems appropriate, or if they insist on pressing the issue, Margaret asks the caller to make the complaint in writing - after all, a professional's livelihood could be at stake. Then, the procedures take the issue out of the complainant's hands. They become an observer to their own complaint. 'We encourage them to stick with it and thank them, because without their complaint, a serious issue may never have come to notice.' 
Rosemarie Khan (Fig. 5) is not popular with her postman. Up to six times a year, he struggles up the path to her door with the papers - a 'huge bundle of them' - for the forthcoming Investigating Committee on which she is due to serve.

Rosemarie is a DCP member of Council who, in her day job, teaches dental hygiene at the Greater Manchester School for DCPs in Salford. Already, as she leafs through the papers she has received, she will have checked for conflicts of interest. Now she has two weekends to plough through all the submissions.

'You have to be detailed and thorough and it takes a lot of work to get through. Our job is to decide whether, if this case were to go to a conduct committee, the dental professional's fitness to practise could be impaired. We filter cases.'

One 'wonderful' innovation for Rosemarie is that 'the case workers type up patients' letters for us, word for word! Sometimes letters can be quite long and anguished and the handwriting is difficult to read. It makes such a difference.'

No lawyers are involved at this point. It is a paper-based exercise. 'When I meet with fellow members of the Investigating Committee, it is with an open mind, because my experience has been that each case is different, often surprising. Colleagues on the committee may offer a completely different viewpoint, which I hadn't thought of. But there are times when we all agree.'

The patient's interests are, as always, paramount. 'It's given me an insight into what patients feel, and feel concerned about. Communication is crucial. So many cases would never have got to us if the dentist had only communicated with the complainant.

'Often I think: there, but for grace of God, go I... One patient had an eye damaged in treatment. We all know that we should insist that patients wear protective spectacles, and no doubt we do, but this is why. This is what can happen.'

Fran Mandel has thought of claiming the money back for the tissues, but never has, although she hands them out often. Really, charming as she is, you don't want to get to know Fran too well. She is one of the ushers for the conduct hearings that take place at the Wimpole Street offices of the GDC, and increasingly elsewhere.

'I do feel sympathetic to the dentists who come before the PCC. They can have a case hanging over them for ages. Sometimes they've got into trouble because they're in the throes of a personal crisis like divorce, and work is the last thing on their minds,' says Fran, who clearly loves her job and has been with the GDC for 14 years. Her humanity and empathy are obvious.

'Of course, we have had dentists burst into tears, particularly if they are unrepresented and lonely. That's where tissues come in useful. I ask if they want to leave for a few minutes - it's human nature to feel sorry for them.'

There was the 'big strapping fellow' who kept breaking down. 'He sobbed almost all the time - in the end they took no action, and I was glad.' One dentist received a verdict and fell over in a dead faint, 'but it was hot that day'. A woman dentist "cried for two or three days. For line after line, the transcript read "sob sob sob... (inaudible)". It is the only occasion on which Fran can recall withholding her tissues - after three days of non-stop tears. 'To be honest, the committee were all men and I think she was just milking it. I lost patience.'

It is not just the dentists for whom Fran feels sorry during conduct cases, but also their partners. She ensures that if necessary couples get private time to talk. Fran's years as witness to a cavalcade of human frailty have given her almost clairvoyant abilities. If you want to know how a case will end, ask Fran.

When good and conscientious professionals get put through the fitness to practise mill, it is tough for them. We understand that. It would be wonderful if someone could invent a justice system in which only the guilty were put on trial. Nobody has yet. In the meantime, the compassion and professionalism of our people helps to make an imperfect system as fair and robust as possible. 